\title{
NHS internal market 1991-2: towards a balance sheet
}

\author{
Roland Petchey
}

The first year of the internal market in the NHS has been claimed to have resulted in increased efficiency. These claims, however, are hard to substantiate because the systems for operating the market are not fully in place. Examination of data on tax relief for private health insurance premiums for over $60 \mathrm{~s}$, general practice fundholding, and implementation and transaction costs suggest that much of the increased efficiency is not due to the reforms but to increased funding. Furthermore, some of the changes seem to be decreasing market forces and reducing efficiency.

Evaluation of the first year's operation of the internal market is not straightforward. The first difficulty is the scale of the reforms, which are generally agreed to be the most wide ranging and fundamental since the inception of the NHS in 1948. Secondly, the white paper $^{1}$ and the working documents ${ }^{2}$ that supplemented it give only the barest outline of the market framework and leave several key issues unresolved. The resultant local variation in working arrangements has greatly complicated national assessment. Thirdly, the first year of implementation presents problems as a basis for evaluation. The market was established before the information on which it depends (population health needs, service costs) was available. As a result most contracting in the first year was in the form of unsophisticated block contracts. Furthermore, the reforms were introduced during the run up to a general election in which it was widely (but incorrectly) expected that health would be the key issue. Accordingly, the NHS Management Executive advised regions and districts against major shifts in service patterns. This resulted in $75 \%$ of contracts being placed with the traditional provider. ${ }^{3}$ Because the pattern of trading in the first year of the market was so confined by technical and political constraints it would be unsafe to generalise from it.

In this article I examine claims that the reforms have improved efficiency by considering three aspects of health services: tax relief on private health insurance premiums for the over $60 \mathrm{~s}$, general practice fundholding, and transaction and implementation costs. These data suggest that the reforms may not be responsible for the improved performance observed.

\section{Increased efficiency or increased funding?}

The difficulties in assessing the internal market already identified did not deter the NHS Management Executive from attempting an evaluation of the first six months of operation. In what was clearly intended as a pre-emptive strike against Labour's expected attack, it claimed the reforms were improving quality and responsiveness and providing "even better value for money." The claims of increased activity were disputed $^{5}$ but were apparently confirmed by the absence of those traditional indicators of NHS inactivity-hospital beds temporarily closed as a year end cost saving exercise. Further apparent corroboration has come from more recent independent statistics. ${ }^{6}$ These show that in 1991-2 inpatient numbers rose $3.5 \%$, day cases $31 \%$, total outpatient attendances $3 \cdot 2 \%$, and new outpatient attendances $2 \cdot 3 \%$ compared with $1990-1$.

Government claims on waiting lists were also substantiated, although allowance has to be made for reductions achieved clerically rather than clinically. But the momentum of reducing waits of over two years does not seem to have been sustained beyond the election and might be partially offset by a rise in waits of between one and two years. ${ }^{7}$ This concern was expressed as early as spring $1991 .^{8}$ Others were anxious that patients with long waits had received priority over those with clinically more urgent conditions..$^{510}$ On balance, though, the evidence suggests record levels of NHS activity during the first year of the internal market.

Before this increased activity is attributed to the internal market, alternative explanations such as increased funding need to be eliminated. Analysis of NHS spending and activity during 1979-92 points strongly towards this possibility (Colin Thunhurst, personal communication). ${ }^{11}$ Whereas there had been virtually zero real growth in NHS funding during the 1980 s, in 1990-1 and 1991-2 NHS spending rose in real terms by $2 \cdot 8 \%$ and $4 \cdot 1 \%$ respectively. In other words almost all the real growth during the decade coincided precisely with the run up to the implementation of the internal market (and the general election). It must, therefore, be included in any explanation of increased activity. Nor can the elimination of two year waits be attributed to the internal market. It is the culmination of a centrally coordinated and continuing "waiting list initiative" begun in July 1986 and costing $£ 156 \mathrm{~m}$. It thus validates not the internal market but "the power of a key ministerial priority and targeted additional funding." Similarly, the rise in day case surgery originates from medical advances and investment decisions that predate the reforms. It cannot be claimed as evidence of their effectiveness.

\section{Tax relief on private health insurance premiums}

Evidence for the effect of tax relief on private health insurance premiums for the over 60 s is fairly secure since the scheme has been operating for two years. Pessimistic early prediction $\mathrm{s}^{12}$ seem to be confirmed by more recent data. Loss of Exchequer revenue has been considerable and has not been offset by any gain in total expenditure on health care. The cost to the Treasury of tax relief was estimated at about $£ 60 \mathrm{~m}$ for the year $1991-2,{ }^{13}$ while the number of people claiming relief was put at $330000 .{ }^{14}$ Insurers also incurred substantial losses. British United Provident Association invested $£ 3 \mathrm{~m}$ in an attempt to tap the expected new market but failed to recover its investment. Western Provident Association spent over $£ 1 \mathrm{~m}$ but recruited just 120 new subscribers. ${ }^{15}$ The scheme has done little to create new
Roland Petchey, non-clinical lecturer

BMF 1993;306:699-701 


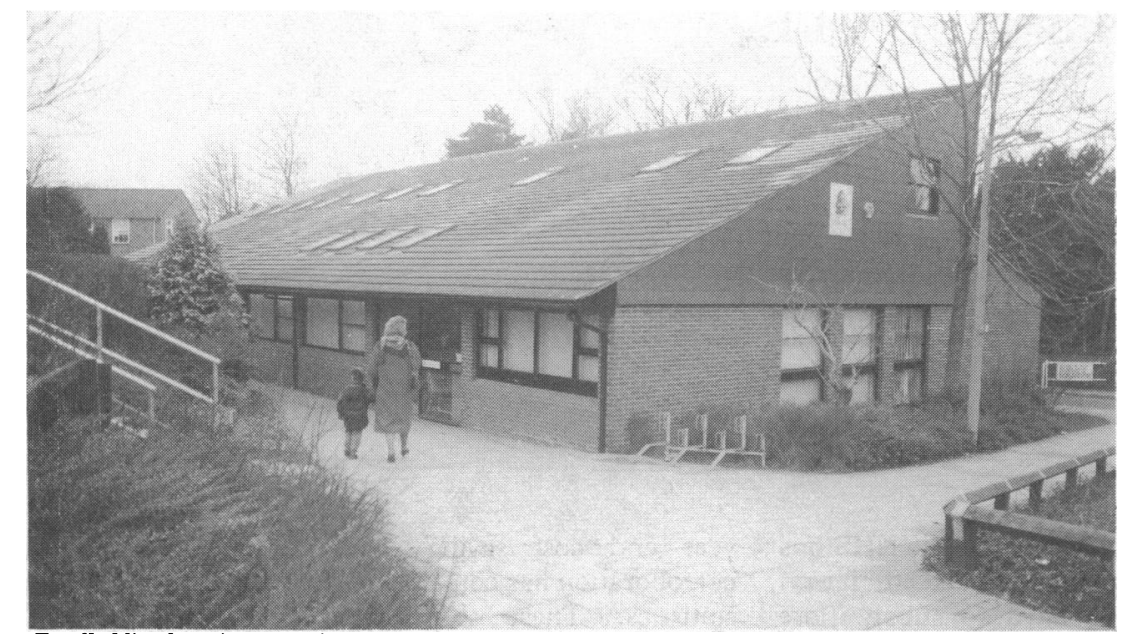

Fundholding has given practices control of their budget but has not reduced variations in spending to switch from non-qualifying to qualifying policies. ${ }^{16}$ demand. It has simply encouraged existing subscribers

The costs of the scheme do not end there, however. Tax subsidisation of private health care will have moved the market away from rather than towards greater efficiency. By lowering the market price from what existing subscribers had already shown they were willing to pay the scheme has decreased the efficiency of this sector of the health care market. As well as reducing efficiency, it will also have reduced equity. People with private health insurance are known to have above average income ${ }^{17}$ and tax relief therefore redistributes purchasing power from lower to higher income groups. Since the wealthy are also likely to be more healthy the scheme also reduces equity of access; the more healthy are ensured privileged access to health care at the expense of those whose need is greater. It is ironic that reforms intended to increase efficiency by introducing market disciplines should have undermined them in the one sector in which they already existed.

\section{General practice fundholding scheme}

The second area of concern is the general practitioner fundholding scheme. Although it is too soon to draw definitive conclusions, some aspects of the scheme raise doubts about the consistency of the government's interpretation of variations in performance. Working for Patients ${ }^{1}$ was not a closely argued and intensively documented analysis of the NHS. It is therefore all the more significant that, among the few statistics it does contain, data on variations in performance between providers feature so prominently- $50 \%$ variation in acute hospital treatment costs, for example, or $100 \%$ variation in general practitioner prescribing costs. In the absence of any reliable direct measure variations were taken as evidence of inefficiency. Eliminating (or at least reducing) variations was a main goal of the reforms.

The budget setting process for fundholding implies a different attitude towards variation. As no formula for capitation funding had been developed fundholders were given budgets on a historical basis. These budgets allowed them to maintain pre-existing activity and referral patterns and have resulted in massive variations in per capita allocations between fundholders. A study of 15 practices in London and the home counties showed variation of over $400 \%$ in drug budgets, over $300 \%$ in hospital inpatient treatment budgets, and $150 \%$ overall. ${ }^{18}$ Similar variation was identified nationally. ${ }^{19}$ It seems unlikely that variations of this magnitude will prove to be correlated with need or deprivation. If it were consistent the government would have to view these variations too as evidence of inefficiency.
It has been claimed that fundholding "has revealed rather than created these variations." 18 I would suggest that it has done rather more than just reveal them. It has reinforced them by building them into practice budgets. Higher spending practices were rewarded for their inefficiency and the more efficient penalised by lower budget allocations. The implication that "easy money" was made available to some fundholders was reinforced by reports in January 1992 that some were expecting six figure savings from their hospital treatment budgets by the end of the financial year. ${ }^{20}$ These expectations are rumoured to be confirmed by an Audit Commission report on fundholding due for publication last September but delayed. ${ }^{21}$ It is hardly surprising that health authorities and hospital managers were calling for the immediate introduction of capitation funding for fundholders as a means of stemming losses from their budgets. ${ }^{22}$

The fundholding scheme has entailed costs for other actors in the internal market. Providers have had to cope with the uncertainty created by the unpredictability of fundholders' purchasing decisions or maintain services on a lower throughput when fundholders referred elsewhere. They have had to develop more detailed service costings than were required by their main customers, the district health authorities, who were limited to the less information costly block contracts during the first year of the internal market. The fact that these costs cannot readily be quantified or fall outside the fundholding sector does not mean that they should be overlooked. Whenever the final balance is drawn up, costs such as these will have to be offset against whatever gains arise from the scheme.

\section{Transaction and implementation costs}

Although critical of the costs of bureaucratic organisation, proponents of markets have paid less attention to the costs of transactions in the market place. ${ }^{23-25}$ When the product or service being exchanged is complex (as is the case with health care), it is either impossible or extremely costly to specify in advance in a written contract every contingency that might affect the transaction. An elderly unstable diabetic patient admitted for surgery, for instance, is obviously going to require more hospital treatment than a younger fitter patient. Because it is difficult to incorporate contingencies of this kind contracts will inevitably be incomplete specifications of the rights and obligations of the contracting parties. Incompleteness creates scope for opportunism. For example, a provider could seek to increase profits by trimming the quality of care or a purchaser to reduce costs by manipulating information or concealing intentions (for instance, about the number of patients it will be referring under a block contract or their health status).

One solution to the problem of incomplete contracts is to try to incorporate as many contingencies as possible. This, however, requires much more information. An alternative is intensified monitoring of performance in an attempt to ensure compliance with contracts. Neither solution is straightforward, given the inherent difficulties of specifying and monitoring compliance with care plans that are essentially "customised" to each patient. Both add significantly to the transaction costs of operating the internal market. If operating the market entails transaction costs, it is even clearer that establishing it entails implementation costs, although the difficulty of identifying and quantifying them means that estimates vary widely. One estimate puts the eventual start up cost of the internal market at $£ 2$ bn and recurring costs at $£ 0.5 \mathrm{bn}$ annually. ${ }^{26}$ Officially, however, only the following implementation costs have been conceded: $£ 79 \mathrm{~m}$ in $1989-90, £ 306 \mathrm{~m}$ in $1990-1$, and an estimated $£ 383 \mathrm{~m}$, in 
1991-2. ${ }^{27}$ To this, though, we would need to add the start up costs of the fundholding scheme $(£ 4.4 \mathrm{~m}$ in $1990-1$ and $£ 8 \mathrm{~m}$ in first six months of $\left.1991-2^{28}\right)$ and the $£ 11 \mathrm{~m}$ estimated cost of creating the asset registers needed for calculating capital charges. ${ }^{29} \mathrm{We}$ should also add some part of the cost of the increased numbers of general and senior managers, which rose from 510 in 1986 to 13200 in $1991,{ }^{3031}$ Between 1987 and 1991 the salary bill for general managers rose from $£ 25.7 \mathrm{~m}$ to $£ 251.5 \mathrm{~m} .{ }^{32}$ These increases must be seen in context. Part of the increased numbers may be nominal (because of changes in title) rather than real. ${ }^{33}$ Salaries of general managers still represent only $2 \cdot 2 \%$ of total wages and salaries in the NHS. Even if we add in the $£ 1.2 \mathrm{bn}$ spent on other administrative and clerical staff as a crude proxy measure of the managerial and administrative "overhead" it amounts still to just under $6 \%$ of total NHS expenditure. ${ }^{32}$ Others have estimated administrative expenditure in the NHS at around 5\%. The NHS has always been considered a "good buy" internationally in terms of administrative costs, and although precise comparisons are not possible, clearly remains so, certainly when compared with the $24 \cdot 1 \%$ calculated for the United States. ${ }^{35}$ Nevertheless, the rate of increase in expenditure on senior management since 1987 is remarkable and the costs are now equivalent to those of running four medium sized health authorities.

We are unlikely ever to be able to quantify transaction and implementation costs with any certainty. None the less, it is clear both that they are substantial and that they have to be offset against any putative gains in efficiency brought about by the internal market. This conclusion is confirmed by recent experience in the United States, where rising costs of administration and regulation are an important factor in the continuing escalation of health care spending. ${ }^{36-38}$ The cost of health service administration in the United States rose by $37 \%$ between 1983 and $1987 .{ }^{35}$ Much of the high administrative overhead in the United States is attributable to the multiplicity of payers and the necessity of assigning treatment costs to individual patients and purchasers. In Britain for the foreseeable future the ultimate purchaser of $80 \%$ or more of health care will continue to be the Treasury. This being so, the question has to be asked: Will the expected benefits of the internal market be sufficient to offset the costs of establishing and operating it?

There is evidence that the government may have substantially underestimated these costs. The financial memorandum published in the NHS and Community Care Bill in $1990^{39}$ set out its official estimate of the financial and personnel effects of the legislation. For items where costs have been disclosed, these estimates have been greatly exceeded. The $£ 14 \mathrm{~m}$ annual budget allowed for establishing fundholding seemed to be heading for overspend just midway through 1991-2. Creating asset registers cost double the $£ 5.5 \mathrm{~m}$ estimated. The acknowleged annual implementation costs referred to earlier were running at almost double the $£ 220 \mathrm{~m}$ estimated for setting up the internal market. The memorandum expressed the government's confidence that the extra costs would be more than covered by the savings they made possible. This confidence seems unjustified, at least as far as capital asset charging is concerned. The whole of the first year was written off as a "shambles." 40

\section{Conclusion}

The NHS is changing but the nature of the change is still unclear. Considerable uncertainty remains about the balance to be struck between the market and hierarchy, between economic forces and political considerations in the determination of health policy.
Politics has predominated hitherto, but its future role is unknown (and probably undecided). Even if this had been determined there would still be formidable technical obstacles to be overcome in realising the managed market in health care, given that the project is unprecedented and unpiloted. Under these circumstances, attempting even an interim assessment of just a few facets of change may appear premature (not to mention hubristic). I would argue that the uncertainties that make evaluation difficult also make it imperative.

Given the scale and complexity of the reforms final analysis may never be possible. However, on the basis of the limited data available, and in the areas that have been considered it seems probable that substantial and largely unrecognised costs have been incurred. What is less certain is whether they have been, or will be, offset by corresponding gains.

1 Secretaries of State for Health, Wales, Northern Ireland, and Scotland. Working for patients. London: HMSO, 1989.

2 Secretaries of State for Health, Wales, Northern Ireland, and Scotland. Working for patients: working papers 1-8. London: HMSO, 1989.

3 National Association of Health Authorities and Trusts. The financial survey 1991. Birmingham: NAHAT, 1991.

4 NHS Management Executive. The NHS reforms: the first six months. London NHSME, 1992.

5 Radical Statistics Health Group. "NHS reforms: the first six months"-proof of progress or a statistical smokescreen? $B M{ }^{\prime}$ 1992;304:705-9.

6 National Association of Health Authorities and Trusts. The financial survey 1992. Birmingham: NAHAT, 1992.

7 Limb M. NHS chiefs deny waiting list drive has suffered post-election breakdown. Health Service Joumal 1992;102 (18 June):6.

8 Health Committee of the House of Commons. Public expenditure on health services: waiting lists. London: HMSO, 1991.

9 Pope C. Trouble in store: some thoughts on the management of waiting lists and the 1990 NHS reforms. BMF 1992;305:577-9.

10 Pope C. Trouble in store: some thoughts on the management of waiting lists. Sociology of Health and Illness 1991;13:193-212.

11 Brindle D. Increase in NHS funding cancelled by demands on budgets. Guardian 1992 May 7:11.

12 Propper C, Maynard A. Whither the private health care sector? In: Culyer A Maynard A, Posnett J, eds. Competition in health care: reforming the NHS London: Macmillan, 1990:48-66.

13 Maude F. Tax relief. House of Commons Official Report (Hansard) 1991 May 1;190:col 215. (No 101.)

14 Maude F. Private health insurance (tax relief). House of Commons Official Report (Hansard) 1991 November 5;198: col 32. (No 4.)

15 Millar B. Broken clock in a bright new wrapping? Health Service fournal 1991;101 (28 February): 17.

16 Laing W. Laing's review of private health care. London: Laing and Buisson, 1992 .

17 Office of Population Censuses and Surveys. General household survey. London HMSO, 1990.

18 Glennerster H, Owens P, Matsaganis M. A foothold for fundholding. London: King's Fund Institute, 1992

19 Day P, Klein R. Variations in budgets of fundholding practices. $B M \mathcal{F}$ 1991;303:168-70.

20 The week. BMF 1992;304:142.

21 Fund-holder's savings expose errors. BMA News Review 1992;18:12,28.

22 Sheldon T. Managers call for per person funding for GPs. Health Service foumal 1992;102(4 June):8.

Williamson O. Markets and hierarchies: analysis and antitrust implications. New York: Free Press, 1975.

24 Bartlett W. Quasi-markets and contracts: a markets and hierarchies perspective on NHS reform. Bristol: SAUS Publications, 1991.

25 Hughes D, Dingwall R. Sir Henry Maine, Joseph Stalin and the reorganisation of the National Health Service. Journal of Social Welfare Law 1991;5: of the Na6-309.

26 Light D. Observations on NHS reforms: an American perspective. $B M \mathcal{F}$ 1991;303:568-70

27 Dorrell S. NHS reforms. House of Commons Official Repont (Hansard) 199 December 6;200:col 245. (No 27.)

28 Dorrell S. GP fundholding. House of Commons Official Report (Hansard) 1992 January 31;202:col 667. (No 52.)

29 Mellett H. Paying for goods that were free. Health Service fournal 1991; 101(7 January): $18-9$

30 NHS managers increase by over $1000 \%$. BMF 1992;304:400.

31 NHS managers' wage bill rises. $B M \mathcal{F} 1992 ; 305: 602$.

32 Department of Health. Health and personal social service statistics for England. London: HMSO, 1992.

London: HMSO, 1992.
33 IHSM queries statistics on manager's pay. Health Service fournal 1992; 102(10 September): 5 .

34 Harrison S. Working the markets: purchaser/provider separation in English health care. Int $\mathcal{F}$ Health Serv 1991;21:625-35.

35 Wollhandler S, Himmelstein D. The deteriorating administrative efficiency of the US health care system. New Engl f Med 1991;324:1253-7.

36 Evans R. Finding the levers, finding the courage: lessons from cost containmen in North America. I Health Polit Policy Law 1986;11:585-615.

37 Hadley J, Langwell K. Managed health care in the US: promises, evidence to date and future direction. Health Policy 1991;19:91-118.

38 Quam L. Post-war American health care: the many costs of market failure. In McGuire A, Fenn P, Mayhew K, eds. Providing health care. Oxford: Oxford University Press, 1991:192-232.

39 National Health Service and Community Care Bill. London: HMSO, 1990 (HL Bill 51.)

40 Moore W. DoH forced to write off year one of NHS capital charges "shambles." Health Service foumal 1991;101(5 December):3.

(Accepted 14 fanuary 1993) 